\title{
MAGMATISMO ALCALINO DO PARAGUAI: UMA REVISÃO E ATUALIZAÇÃO DAS PROVÍNCIAS
}

\author{
V.F.Velázquez'; C.B.Gomes ${ }^{2}$; D.Orué ${ }^{3}$; P.Comin-Chiaramonti ${ }^{4}$
}

PALAVRAS-CHAVE: Paraguai Oriental, rochas alcalinas, províncias alcalinas.

VELÁZQUEZ, V.F. et al. (1996) Magmatismo alcalino do Paraguai: uma revisão e atualização das provincias, Bol.IG-USP, Sér.Cient, 27:61-79.

\section{RESUMO}

O evento tectono-magmático nas bordas da Bacia do Paraná, na região sudoeste do Brasil (Mato Grosso do Sul) e Paraguai Oriental, é marcado pela existência de numerosos focos de rochas alcalinas. $O$ acúmulo de conhecimentos nos últimos anos sobre esse magmatismo, que se estende desde o Permo-Triássico ao Oligoceno, tornou indispensável a sua revisão, bem como levou à formulação de uma proposta mais atualizada de agrupamento das ocorrências conhecidas, com base principalmente em evidências petrográficas, geoquímicas e geocronológicas.

Embora as informaçōes sobre algumas ocorrências ainda se mostrem insatisfatórias, os dados disponiveis permitem a definiçăo de seis províncias (Alto Paraguai, Rio Apa, Amambay, Central, Misiones e Assunção), caracterizadas por diferenças marcantes no tocante à composição das rochas e época de colocação na crosta dos numerosos corpos. Ainda que no Paraguai sejam poucos os trabalhos que relacionam a distribuição geográfica do magmatismo com os elementos tectônicos, três tipos principais de associaçăo são sugeridas: a) margem cratônica ou área tectonicamente estável, caso das Provincias Alto Paraguai e Rio Apa; b) zona de arcos estruturais ou intercessåo de alinhamentos tectônicos, como exemplificado pela Provincia Amambay e c) rift continental, caso das Provincias Central, Misiones e Assunção.

\section{ABSTRACT}

The tectonic-magmatic event at the border of the Parana basin in southern Brazil (Mato Grosso do Sul State) and Eastern Paraguay is evidenced by the existence of several foci of alkaline rocks. The recent accumulation of knowledge on this magmatism, active between the Permo-Triassic and Oligocene, makes it crucial that it be reviewed and leads to an updated proposal for assembling the known occurrences mainly on the basis of petrographic, geochemical and geochronological evidence.

Despite unsatisfactory information on some occurrences, the available data allow definition of six provinces (Alto Paraguay, Rio Apa, Amambay, Central, Misiones and Asunción), each characterized by remarkable differences in rock composition and time of emplacement into the crust. Although little work has been done in Paraguay on the relation between geographic distribution of the alkaline magmatism and tectonic elements, three main types of association can be suggested: a) cratonic margins or tectonically stable areas, for example, the Alto Paraguay and Rio Apa Provinces; b) structural

\footnotetext{
'Aluno Pós-Graduando, IGJUSP.

${ }^{2}$ Departamento de Mineralogia e Petrologia, Instituto de Geociências/USP, São Paulo, Brasil.

${ }^{3}$ Facultad de Ciencias Exactas e Naturales, Universidad Nacional de Asunción, Assunção, Paraguai.

'Dipartimento di Ingegneria Chimica, dell'Ambiente e delle Materie Prime, Università di Trieste, Trieste, Itália.
} 
arcs or tectonic alignment, exemplified by the Amambay Province, and c) continental rift, as is the case for the Central, Misiones and Asunción Provinces.

\section{INTRODUÇÃO}

$\mathrm{O}$ evento tectono-magmático nas bordas da Bacia do Paraná, em especial junto ao seu flanco ocidental, na região sudoeste do Brasil (Mato Grosso do Sul) e Paraguai Oriental, se caracteriza pela existência, a partir do Permiano Superior, de numerosos focos de rochas alcalinas. No Cretáceo Inferior, a parte centro-oriental do Paraguai esteve sujeita a manifestações igneas, dominantemente efusivas, de caráter toleítico. Entretanto, no Jurássico Superior ao Cretáceo Inferior, sobretudo no último periodo, a atividade alcalina ganhou maior intensidade, gerando diversos corpos intrusivos e efusivos que se concentraram principalmente nas regiões central e nordeste do pais. Posteriormente, no Cenozóico, após um período geológico relativamente calmo e ainda em um ambiente marcadamente sedimentar, teve lugar a última manifestação magmática, esta responsável pela intrusão de rochas ultrabásicas alcalinas de afinidade sódica e portadoras de nódulos mantélicos, que afloram principalmente nas circunvizinhanças da cidade de Assunção.

Os primeiros estudos geológicos sobre as ocorrências alcalinas paraguaias e da região sudoeste do Brasil constam dos trabalhos de Evans (1894) e Derby (1896), onde se descreve sucintamente a petrografia de amostras coletadas na localidade de Pão de Açúcar. Ainda que tenham sido feitas outras pesquisas sobre essas rochas, os dados disponíveis são todavia limitados e, somente na década dos 50, começaram a surgir alguns trabalhos de conotação mais geológica. Assim, Moraes (1958) e Guimarães (1958) trouxeram informações referentes aos corpos do Fecho dos Morros e Pão de Açúcar, enquanto que
Eckel (1959) investigou diversos outros quanto à petrografia e possível existência de mineralizações associadas. Adicionalmente, Putzer (1962) efetuou levantamento geológico de alguns maciços e realizou estudos petrográficos dos principais tipos de rochas encontradas.

Posteriormente a essa etapa pioneira, foram executados alguns trabalhos mais minuciosos, como, por exemplo, aqueles focalizando as ocorrências da área de Sapucai, onde Palmieri (1973) e Palmieri \& Arribas (1975) reuniram descrições petrográficas gerais e forneceram uma discussão sobre a geoquímica e geocronologia das litologias coletadas. Mariano (1978), dentro do Programa Exploração Mineral do Paraguai conduzido pela empresa Anschutz Corporation, descreveu várias ocorrências alcalinas, ainda que tenha se concentrado preferencialmente na área de Pedro Juan Caballero, na porção nordeste do país. Em seu relato, procurou destacar a potencialidade econômica dessas rochas, valendo-se para tanto de dados petrográficos e análises químicas. Ainda ligado a essa empresa foram também produzidos diversos trabalhos, ainda hoje existentes na forma de relatórios internos no Ministério de Obras Públicas (p.e. Hutchison, 1979, 1980; Hales, 1980).

Ao lado das referências anteriores, citam-se ainda os trabalhos de Stormer at al. (1975), Bitschene \& Lippolt (1984), Bitschene et al. (1986) e Bitschene (1987), este último focalizando a região de Ybytyruzú e trazendo informações petrográficas, tectônicas, estratigráficas e geocronológicas, além de ampla discussão sobre a gênese das rochas alcalinas ali aflorantes. Por outro lado, os trabalhos de Livieres (1987) e 
Censi et al. (1989) foram fundamentais para o melhor conhecimento do complexo alcalino carbonatítico de Cerro Chiriguelo. Os últimos autores, com base em dados geoquímicos, trataram da origem e evolução do magma carbonatítico.

Dentro do programa de cooperação internacional iniciado em setembro de 1987 , e que vem contando com a participação de pesquisadores de instituições universitárias do Brasil, Itália e Paraguai, foram se intensificando as investigações sobre as rochas alcalinas do Paraguai. A primeira contribuição efetiva do grupo correspondeu ao estudo realizado por Gomes et al. (1989) sobre a atividade filoniana na área de Sapucai, enquanto que vários outros trabalhos de cunho geoquímico foram desenvolvidos junto às demais ocorrências da Província Central, destacando-se, entre eles, os de Velázquez et al. (1990), Comin-Chiaramonti et al. (1991a, 1992a) e Censi et al. (1991); além disso, registre-se também os estudos de interesse mais geocronológico (p.e. Velázquez 1992; Velázquez et al., 1990, 1992). Mais recentemente, esse grupo de pesquisadores passou também a se ocupar das ocorrências alcalinas da Província Alto Paraguai, sendo os primeiros resultados publicados em Gomes et al. (1993) e Velázquez et al. (1993).

Nessa breve retrospectiva histórica, cabe ainda mencionar o trabalho de Gomes et al. (1996), que se constitui na mais recente revisão do magmatismo alcalino do Paraguai. Ainda que datado de 1996 , essa contribuição traz em realidade informações disponíveis até o final de 1992

\section{EVOLUÇÃO DO CONCEITO DE PROVINCIA ALCALINA}

Diversos autores se preocuparam em tratar o magmatismo alcalino do $\mathrm{Pa}$ raguai dentro de um contexto mais ge- ral. O primeiro trabalho a oferecer essa visão foi o de Putzer (1962), onde é feita breve descrição e listagem dos principais corpos até então conhecidos do que ele denominou magmatismo alcalino pós-triássico da região oriental e ocidental do Paraguai.

Mais tarde, Almeida (1971), baseado em evidências estruturais, reuniu as diversas ocorrências alcalinas brasileiras, incluindo-se aí os centros eruptivos do Jurássico e Cretáceo situados a SE de Assunção, em oito grupos. Ulbrich \& Gomes (1981), com base em dados geológicos e petrográficos, propuseram a classificação das alcalinas do Brasil em oito províncias, estando as ocorrências paraguaias incluídas na Província do Mato Grosso. Almeida (1983), ao discutir a reativação Wealdeniana e o magmatismo alcalino na porção meridional da Plataforma Sul-Americana, fez menção à existência de numerosas intrusões alcalinas no Paraguai, ocupando basicamente duas regiōes distintas, central e oriental do país, agrupadas e descritas sob a denominação de Província Paraguai Oriental. Ainda, o Projeto PAR 83/005 (1986), valendo-se de conceitos estratigráficos, e tomando como localidade tipo as atividades alcalinas de Sapucai, procurou enquadrar as diversas ocorrências (alcalinas potássicas, carbonatíticas e ultramáficas) na Formação Sapucai.

Até então, as manifestações alcalinas do Paraguai haviam sido apenas agrupadas com base na área de ocorrência e evidências geológicas. Contudo, não existia ainda uma divisão clara para esse magmatismo, o que acabou acontecendo somente com o trabalho de Livieres \& Quade (1987). Surgiria daí a primeira denominação de "província alcalina" propriamente dita para um conjunto de 32 corpos conhecidos na época, e agrupados em três províncias: Alto Paraguai, Amambay e Central. 
No decorrer do tempo, os conhecimentos sobre esse magmatismo foram se acumulando e levaram à descoberta de novas ocorrências. Hoje, a literatura dispõe de informações que permitem distinguir as suas feições mais gerais, sendo mesmo possível avaliar com maior clareza as associações petrográficas, as características geoquímicas e as diferenças cronológicas existentes. Por tudo isto, considera-se importante efetuar uma revisão do assunto, de forma a estender o conceito de província alcalina no Paraguai. Dentro dessa perspectiva, apresenta-se aqui uma proposta mais atualizada de agrupamento dessas ocorrências, com base principalmente nos seus aspectos geocronológicos, geoquímicos e petrográficos.

$\mathrm{Na}$ Tabela 1, acham-se reunidos os diversos corpos e complexos alcalinos conhecidos do Paraguai e da área limítrofe com o Mato Grosso do Sul, com algumas de suas características mais relevantes, e na Figura 1 é fornecida a sua localização geral.

\section{Província Alto Paraguai}

Essa denominação foi empregada primeiramente por Livieres \& Quade (1987) para agrupar rochas aflorando nas localidades San Carlos e Cerro Buena Vista, além das ácidas ignimbríticas de Fuerte Olimpo (hoje sabidamente pré-cambrianas), na porção norte do pais. No presente trabalho, incluem-se apenas as ocorrências situadas geograficamente na divisa do Estado Mato Grosso do Sul com o Paraguai e comcentradas ao longo do rio Paraguai, principalmente nas imediações das localidades de Puerto Coeyú (Paraguai) e Porto Murtinho (Brasil) (Fig. 1A). Ali afloram como pequenos stocks, plugs e na forma de verdadeiros corpos intrusivos de caráter anelar, caso particular dos complexos do Cerro Siete Cabezas (Paraguai) e Pão de Açúcar (Brasil), este último representando a feição topo- gráfica mais expressiva da região.

Diversos trabalhos pioneiros de cunho eminentemente petrográfico (Evans, 1894; Derby, 1896) classificaram - material proveniente da intrusão de Pão de Açúcar como sendo constituído de sienito augítico. Moraes (1958) e Guimarães (1958) caracterizaram as amostras coletadas na área de Fecho dos Morros como foiaitos e sienitos, enquanto que Putzer (1962) descreveu Cerro Boggiani como formado dominantemente de rochas sieníticas portadoras de nefelina e sodalita.

O Projeto Bodoquena (1979), investigando as ocorrências alcalinas associadas à área de Fecho dos Morros, indicou a existência de sienitos, traquitos e traquiandesitos. Pouco depois, o Projeto Radambrasil (1982) trouxe informaçōes sobre os corpos de Fecho dos Morros e Pão de Açúcar, onde foram descritas rochas do tipo sienito, latiandesito e traquito, além de biotita-egirina sienito e egirina-arfvedsonita sienito.

Os estudos geoquímicos, ainda escassos, tiveram como primeiro registro na literatura o trabalho de Putzer \& van den Boon (1962), reunindo dados de elementos maiores para os corpos mais conhecidos. Mais recentemente, mencione-se a contribuição de Gomes et al. (1993), oferecendo grande acervo de dados químicos. Nesta, os autores reconheceram, em função do grau variável de saturação em sílica, dois grupos distintos de rochas sieníticas, sugerindo, ainda, que essas suítes poderiam estar relacionadas a diferentes linhas de evolução petrogenética.

A primeira informação sobre a idade desse evento magmático é encontrada em Amaral et al. (1967), trazendo quatro datações pelo método $\mathrm{K} / \mathrm{Ar}$ (média, $226 \mathrm{Ma}$ ) para uma única amostra de nefelina sienito da intrusão de Pão de Açúcar. Também no artigo de Comte \& Hasui (1971) existe uma idade de $209 \mathrm{Ma}(\mathrm{K} / \mathrm{Ar}$, rocha total em fono- 
lito) para a mesma localidade. Outra fonte de dados é o trabalho de Velázquez et al. (1993), reunindo idades obtidas pelas metodologias $\mathrm{K} / \mathrm{Ar}$ e $\mathrm{Rb} / \mathrm{Sr}$ em rochas sieníticas. Duas dizem respeito ao corpo de Cerro Boggiani, com idade de $234 \mathrm{Ma}$ (K/Ar, anfibólio) e $223 \mathrm{Ma}(\mathrm{Rb} / \mathrm{Sr}$, isócrona interna), e as outras referem-se às ocorrências de Pão de Açúcar (248 Ma, K/Ar, biotita), Ilha Fecho dos Morros (225 Ma, Rb/Sr, isócrona interna), Cerrito (253 Ma, K/Ar, biotita) e Cerro Siete Cabezas (253 Ma, $\mathrm{K} / \mathrm{Ar}$, biotita).

\section{Província Rio Apa}

As rochas alcalinas pertencentes à Província Rio Apa (Fig.1B) afloram ao

Tabela 1 - Características gerais e localização dos corpos alcalinos do Paraguai.

\begin{tabular}{llll} 
Localidade & Ocorrencia & Rocha & Afinidade \\
& & & \\
& & \multicolumn{2}{c}{ Provincia Alto Paraguai } \\
1- Cerro Boggiani & Stock, plug, dique & NS, F, T & Alcalina sódica \\
2- Påo de Açúcar & Complexo subanelar & NS, F, T & Alcalina sódica \\
3- Ilha Fecho dos Morros & Stock, dique & NS, F & Alcalina sodica \\
4- Cerrito & Stock, dique & NS, F & Alcalina sódica \\
5- Morro Săo Pedro & Stock & SA & Alcalina sódica \\
6- Cerro Pedreira & Stock, dique & SA, QS, T & Alcalina sódica \\
7-Cerro Siete Cabezas & Intrusăo anelar & SA, NS, T & Alcalina sódica \\
8- Satelite I & Stock & SA, QS, Sg & Alcalina sódica \\
9- Satelite II & Stock & SA, QS, Sg Alcalina sódica
\end{tabular}

Condicionamento Periodo
tectỏnico

Cráton Amazỏnico Craton Amazónico Cráton Amazonico Cráton Amazônico Cráton Amazönico Craton Amazónico Cráton Amazőnico Cráton Amazônico Craton Amazônico

\section{Permo-Triássico} Permo-Triássico Permo-Triássico Permo-Triássico Permo-Trilissico Permo-Triassico Permo-Triássico Permo-Triássico Permo-Triatssico

\section{Província Rio Apa}

$\begin{array}{ll}\text { 10- San Lazaro } & \text { Dique } \\ \text { 11- Cerro Santa Elena } & \text { Dique } \\ \text { 12- Cerro Vallemi } & \text { Dique } \\ \text { 13- San Carlos } & \text { Plug } \\ \text { 14- Cerro Buena Vista } & \text { Dique }\end{array}$

$\begin{array}{ll}\text { L ? } & \text { Alcalina } \\ \text { C } & \text { Alcalina-carbonatitica } \\ \text { C } & \text { Alcalina-carbonatitica } \\ \text { F } & \text { Alcalina } \\ \text { F } & \text { Alcalina }\end{array}$

Arco de Aps Arco de Apa Arco de Apa Areo de Apa Arco de Apa

\section{Juro-Cretaceo Juro-Cretáceo Juro-Cretaceo Juro-Cretáceo Juro-Cretáceo}

Provincia Amambay

$\begin{array}{llll}\text { 15- Cerro Chiriguelo } & \text { Complexo anelar } & \text { C, NS, Fe } & \text { Alcalina-carbonatitica } \\ \text { 16- Arroyo Gasory } & \text { Dique } & \text { T } & \text { Alcalina } \\ \text { 17- Cerro Sarambi } & \text { Complexo anelar } & \text { P, NS, F, C } & \text { Alcalina-carbonatitica } \\ \text { 18- Cerro Apuá } & \text { Plug } & \text { T } & \text { Alcalina } \\ \text { 19-Cerro Pero } & \text { Dique } & \text { T } & \text { Alcalina } \\ \text { 20- Cerro Tayay } & \text { Stock } & \text { U } & \text { Mafica-alcalina } \\ \text { 21- Cerro Guazi } & \text { Dique } & \text { L, T } & \text { Máfica-alcalina } \\ \text { 22- Arroyo Blanco } & \text { Dique } & \text { Sh } & \text { Alcalina }\end{array}$

Arco de Ponta Pora Aco de Ponta Pord Juro-Cretaceo Arco de Ponta Pord Juro-Cretticeo Arco de Ponta Pora Juro-Cretáceo Arco de Ponta Pora Juro-Cretaceo Arco de Cap. Bado Juro-Cretáceo Arco de Cap. Bado Juro-Cretáceo Arco de Cap. Bado Juro-Creticeo

Provincia Assunçăı

$\begin{array}{lll}\text { 23- Cerro Verde } & \text { Plug } \\ \text { 24- Villa Hayes } & \text { Plug } \\ \text { 25-Cerro Confuso } & \text { Plug } & \text { Dique } \\ \text { 26- Limpio } & \text { Dique } & \\ \text { 27- Remanso Castillo } & \text { Dique } & \\ \text { 28- San Jorge } & \text { Lava } & \\ \text { 29- Jardin Botanico } & \text { Plug } & \\ \text { 30- Cerro Tacumbú } & \text { Plug } & \text { Nique }\end{array}$

Alcalina sódica Alealina sódię Alcalina sódics Alcalina sódica Alcalina sódica Alcalina sodica Alcalina sódica Alcalina sódies Alcalina sódica Alcalina sódica Alcalina sodica
Rift de Assunçđo Terciário

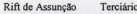
Rift de Assunçăo Terciário Rift de Assunçalo Terciário Rift de Assunção Terciàrio Rift de Assunçăo Terciário Rift de Assunçlo Terciário Rift de Assunç̧̄o Terciärio Rift de Assunçato Terciario Rift de Assunçalo Terciário Rift de Assunçđ̃o Terciărio 
Tabela 1 (conclusão).

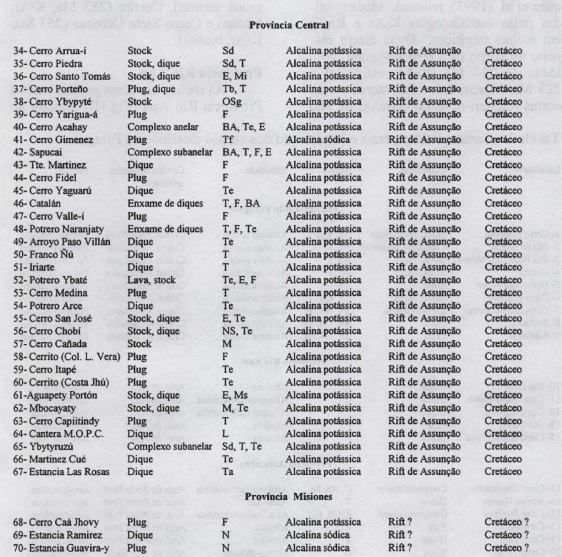

Abreviaçoes: BA, basalto alcalino; C, carbonatito; E, essexito; F, fonolito; Fe, fenito; L, lamprófiro; M, malignito; Mi, minette; Ms, microssienito; N, nefelinito; NS, nefelina sienito; OSg, olivina sienogabro; $\mathrm{P}$, piroxenito; QS, quartzo sienito; $\mathrm{SA}$, sienito alcalino; Sd, sienodiorito, Sg, sienogranito; Sh, shonkinito; $\mathrm{T}$, traquito; Tat traquiandesito; Tb, traquibasalto; $\mathrm{Te}$, tefrito; $\mathrm{Tf}$, traquifonolito; U, ultramáfica

norte do Departamento de Concepción, em duas áreas distintas. Na porção oeste, distinguem-se rochas predominantemente máficas, que incluem diques de afinidade carbonatítica e lamprofirica. Elas ocorrem em San Lazaro, nas imediaçōes de Puerto Vallemi, junto às localidades denominadas de Cerro Santa
Elena e Cerro Vallemí. Os diques apresentam orientação preferencial para NE e possuem como material encaixante uma seqüência de rochas carbonáticas, com termos clásticos subordinados, do Grupo Itapucumi, equivalente ao Grupo Corumbá no Brasil. Por outro lado, mais em direção à área central foram até 


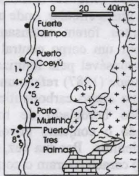

(A) Provincia Atto Paragual

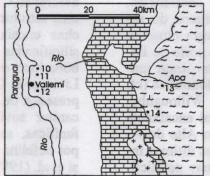

(B) Provincia Rio Apo

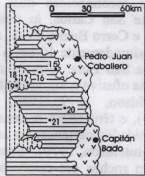

(C) Provincio Amombor
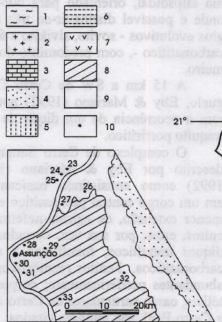

(D) Provincia Assunçáo
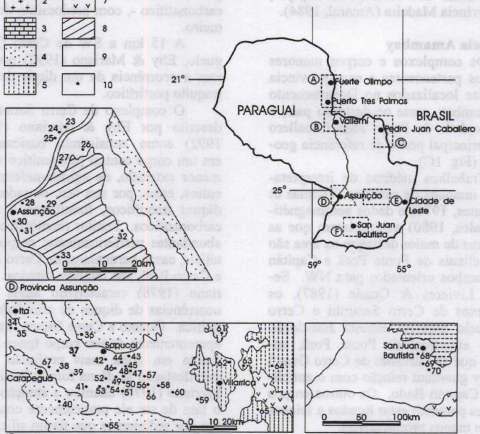

(E) Provincia Central

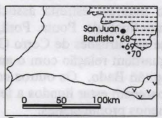

(F) Provinclo Msiones

Figura 1 - Mapa de localização das ocorrências de rochas alcalinas da Provincia Alto Paraguai, incluindo as amostras analisadas para fins geoquímicos (extraído de Velázquez, 1996). Legendas: 1. Pré-Cambriano Inferior, Complexo Rio Apa; 2. Pré-Cambriano Superior, Suite Intrusiva Alumiador; 3. Sedimentos Cambrianos, Grupo Itapucumi; 4. Sedimentos Silurianos, Grupo Caacupé; 5. Sedimentos Carboniferos, Grupo Cerro Corá; 6. Sedimentos Triássicos, Formaçåo Misiones; 7. Magmatismo toleitico JuroCretáceo, Formação Alto Paraná; 8. Sedimentos Terciários, Formaçăo Patiño; 9. Sedimentos Quaternários; 10 . Ocorrências alcalinas. 
então reconhecidas duas ocorrências, Fuerte San Carlos, às margens do rio Apa, e Cerro Buena Vista, esta situada a aproximadamente $10 \mathrm{~km}$ a norte de Estancia San Luís. Ambas mostram tendência efusiva e afinidade fonolítica (cf. Hutchison, 1979, 1980; Willoughby, 1979), e têm como material encaixante as unidades pertencentes ao Alto do Apa (Hutchison, 1979). Estas últimas incluem rochas pré-cambrianas policiclicamente trabalhadas, que se dispõem numa longa faixa NS avançando pelo território brasileiro, onde a unidade recebe o nome de Província de Tapajós, Subprovincia Madeira (Amaral, 1984).

\section{Província Amambay}

Os complexos e corpos menores alcalinos pertencentes a essa província acham-se localizados no Departamento de Amambay, parte nordeste do país, e têm a cidade de Pedro Juan Caballero como principal ponto de referência geográfica (Fig. 1C).

Trabalhos inéditos de interpretação de imagens de satélites (Thomas \& Associates, 1976) e dados aeromagnéticos (Hales, 1980) evidenciaram que as estruturas de maior destaque na área são os anticlinais de Ponta Porã e Capitán Bado, ambos orientados para NW. Segundo Livieres \& Quade (1987), os complexos de Cerro Sarambí e Cerro Chiriguelo mantêm estreita associação com 0 anticlinal de Ponta Porã, enquanto que as intrusões de Cerro Guazú e Tayay guardam relação com o anticlinal de Capitán Bado. Os outros corpos menores parecem estar ligados a feições lineares menos pronunciadas.

Como características marcantes da Província Amambay, citam-se a forma anelar dos complexos, como os citados acima, apresentando diâmetro variável de 5 a $10 \mathrm{~km}$, e a ocorrência de rochas carbonatíticas.

Os complexos mostram enorme diversidade litológica. Mariano (1978) descreveu Cerro Chiriguelo como sendo uma estrutura ígnea circular, onde as rochas encaixantes foram intensamente silicificadas por um corpo central carbonatítico responsável pela fenitização. Livieres \& Quade (1987) referiram-se à presença de um corpo carbonatítico de caráter sovítico bordejado de rochas feníticas, sendo o conjunto envolvido por nefelina sienitos. Por sua vez, Censi et al. (1989) caracterizaram o complexo como um corpo carbonatítico de forma elipsoidal, orientado para NE-SW, onde é possivel distinguir-se três estágios evolutivos - sovito, alvikito e ferrocarbonatítico -, com predomínio do primeiro.

A $15 \mathrm{~km}$ a SW de Cerro Chiriguelo, Eby \& Mariano (1992) noticiaram a ocorrência de um dique de tipo traquito porfirítico.

O complexo de Cerro Sarambí é descrito por Eby \& Mariano (1986, 1992) como consistindo basicamente em um corpo central piroxenítico e, em menor extensão, de egirina-nefelina sienitos, estes, por sua vez, cortados por diques traquíticos, fonolíticos e veios carbonatíticos. Fenitos reomórficos são abundantes perifericamente; corpos satélites, casos particulares de Cerro Apuá e Cerro Perõ, são também citados. Mariano (1978) caracterizou ainda duas ocorrências de diques de afinidade traquítica. Quanto a Cerro Guazú, trata-se aparentemente de um corpo ígneo localizado em zona mais profunda, cuja manifestação se dá na forma de diques. Mariano (1978) chamou a atenção para o fato de ser ele praticamente constituido por sedimentos que foram silicificados e, em alguns casos, até fenitizados. Ainda mencionou a ocorrência de rochas lamprofiricas no seu flanco noroeste, assim como a presença de shonkinitos, distantes aproximadamente $1 \mathrm{~km}$ da localidade de Arroyo Blanco. Desconhece-se a ocorrência em superficie de rochas de afinidade carbonati- 
tica, porém, Eby \& Mariano (1992) suspeitam da sua existência em profundidade, com base em evidências geofisicas e anomalias geoquímicas de Terras Raras.

O trabalho de Livieres (1987) oferece um panorama geral sobre a geoquímica do complexo de Cerro Chiriguelo. Segundo esse autor, as rochas sieníticas são heterogêneas, ligeiramente miasquíticas, além de portadoras de concentrações elevadas em elementos incompativeis $(\mathrm{Pb}, \mathrm{Ba}, \mathrm{Ce}, \mathrm{La}, \mathrm{Nb}, \mathrm{Th}$, $\mathrm{Zr}$ e U) e teores baixos em $\mathrm{Cr}$ e Ni. Já as rochas carbonatíticas caracterizam-se por apresentar conteúdos elevados em $\mathrm{Ca}, \mathrm{Ba}$ e $\mathrm{CO}_{2}$ e baixos em $\mathrm{Mg}, \mathrm{Sr}, \mathrm{Nb}$, $\mathrm{U}$ e $\mathrm{Zr}$.

Censi et al. (1989) obtiveram teores elevados em $\mathrm{Ca}$ e $\mathrm{Ba}$ para as rochas do complexo. Observaram também que a abundância em $\mathrm{Nb}$, U e Th guarda relação com rochas carbonatíticas portadoras de urâniopirocloro. Os fenitos exibem teores elevados de $\mathrm{K}$ em relação a $\mathrm{Na}$. Adicionalmente, com base na concentração dos isótopos de $\mathrm{C} \mathrm{e} \mathrm{O}$, sugeriram que a evolução do carbonatito teria se dado em ambiente vulcânico e subvulcânico.

Trabalhos geocronológicos sobre a Província Amambay são ainda raros na literatura. Os primeiros dados disponíveis (método K/Ar) são os de Comte \& Hasui (1971) para a ocorrência de Arroyo Gasory: $143 \pm 8 \mathrm{Ma}$ (rocha total) e $135 \pm 7 \mathrm{Ma}$ (biotita) para um traquito. Mariano (1978), em seu relatório sobre pesquisa mineral, reportou duas idades K/Ar em biotita: a primeira, $128 \pm 5 \mathrm{Ma}$, relativa ao carbonatito de Cerro Chiriguelo e a segunda, $117 \pm \mathrm{Ma}$, a um shonkinito proveniente da localidade de Arroyo Blanco.

Eby \& Mariano (1992) forneceram alguns dados radiométricos para diversos corpos da Província Amambay. Idades de $118 \pm 20$ e $125 \pm 12 \mathrm{Ma}$ foram obtidas por traços de fissão em apatita em carbonatito transgressivo do Cerro Chiriguelo. Para Cerro Guazú, os valores conseguidos foram $117 \pm 4 \mathrm{Ma}$ (K/Ar, biotita) e $114 \pm 15 \mathrm{Ma}$ (traços de fissão), enquanto que para Cerro $\mathrm{Sa}$ rambí as idades $(110 \pm 10$ e $86 \pm 2 \mathrm{Ma}$, ambas por traços de fissão) mostraram enorme discrepância. Para as demais ocorrências, Arroyo Gasoy e Cerro Apuá, os valores reunidos foram $146 \pm 12$ Ma (traços de fissão em titanita) para a primeira, e $133 \pm 12$ e $114 \pm 15 \mathrm{Ma}$ (traços de fissão em apatita) para a segunda.

\section{Província Central}

Essa atividade engloba grande número de corpos (Fig. 1E), ocupando quase sempre as partes mais elevadas da região, e, topograficamente, aparecendo na forma de cerros, com altura entre 100 e $500 \mathrm{~m}$, ou pequenas colinas. A sua ocorrência é das mais variadas, sendo possivel distinguir-se desde pequenos diques, plugs, stocks, lavas, até verdadeiras massas intrusivas de características anelares (p.e. Cerro Acahay: diâmetro $5 \mathrm{~km}$, borda saliente e depressão central). Tectonicamente, estão ligados ao rift de Assunção (DeGraff, 1985), uma estrutura orientada para NW-SE que se estende por cerca de $200 \mathrm{~km}$ de comprimento e 35 a $40 \mathrm{~km}$ de largura.

Nos poucos casos observados, verifica-se que o contato desses corpos com as encaixantes sedimentares regionais se dá com ausência de maior atividade metamórfica, capaz de produzir alteraç̋̃es mineralógicas e químicas, assim como de deformações estruturais expressivas. Quanto muito reconhecem-se feições indicativas de recristalização ou silicificação parcial dos arenitos na zona de contato (p.e. Cerro Acahay). Em raras oportunidades (pedreiras), foram encontradas evidências de contato de natureza tectônica.

As ocorrências alcalinas exibem enorme diversidade petrográfica. A fácie intrusiva reúne sobretudo variedades 
de afinidade sienogábrica (gabros essexíticos, essexitos, sienodioritos), sendo a textura em geral faneritica, hipidiomórfica granular a ligeiramente porfirítica (plagioclásios e/ou piroxênios como fenocristais). Subordinadamente, aparecem tipos sieníticos (sienitos, nefelina sienitos) com textura fanerítica alotriomórfica, e contendo, como constituintes máficos mais comuns, piroxênios, olivina, biotita e anfibólios; junto aos tipos mais félsicos, predominam plagioclásios (suíte gábrica) e feldspato potássico (suíte sienítica). Como acessórios podem ser citados apatita, titanita, opacos e, eventualmente, zircão. Por sua vez, a fácie efusiva (lavas e plugs) é caracterizada pela presença de rochas de afinidade basáltica e traquibasáltica, ao lado de algumas amostras de composição mais tefrítica, exibindo forte tendência porfirítica. Nestas, os fenocristais possuem dimensões milimétricas a centimétricas e são, em sua maior parte, representados por piroxênios, plagioclásio e, mais raramente, olivina e fóides, imersos em matriz afanitica de caráter holocristalina (Velázquez, 1992).

Os enxames de diques constituem a feição geológica mais proeminente associada ao ambiente hipoabissal. Os trabalhos de campo na área de Sapucai, por exemplo, permitiram reconhecer mais de 200 corpos correspondendo a fases distintas de geração (Gomes et al., 1989; Comin-Chiaramonti et al., 1991b, d, 1992a). Em geral, os corpos são verticais a subverticais e de espessura decimétrica a métrica, com valor médio da ordem de 4 a $6 \mathrm{~m}$. Recortam indistintamente as demais rochas alcalinas, assim como as sedimentares encaixantes. Sua orientação preferencial é NW-SE, contudo, duas outras direções, NS e NE$\mathrm{SW}$, foram também reconhecidas.

Do ponto de vista petrográfico, os diques demonstram grande diversidade mineralógica e textural, permitindo a caracterização de vários tipos litológi- cos: basaltos alcalinos, tefritos, traquiandesitos, traquifonolitos, traquitos e fonolitos. Como tendência geral, essas rochas apresentam forte caráter porfiritico, notadamente as variedades de natureza tefrítica e fonolítica, com mega, feno e microfenocristais dos mais variados minerais. A matriz é comumente afanitica, e de caráter preferencialmente holocristalina. Os traquiandesitos são frequientemente microporfiríticos, enquanto que os traquitos se mostram porfiríticos e portadores de cristais tabulares de feldspato potássico com forte orientação (De Min, 1988; Gallo, 1988; Comin-Chiaramonti et al., 1990).

Ao lado da caracterização petrográfica das rochas alcalinas potássicas, alguns trabalhos dando maior ênfase à geoquímica foram também desenvolvidos, entre os quais se destaca o de Palmieri \& Arribas (1975), fornecendo uma primeira visão do evento magmático do complexo alcalino de Sapucai. Posteriormente, Bitschene (1987), em programa de levantamento geológico na área de Ybytyruzú, teceu comentários sobre a tectônica, estratigrafia e geocronologia, além de discutir com base em dados geoquímicos a gênese das rochas alcalinas aflorantes. Esse autor procurou chamar a atenção para a concentração elevada em $\mathrm{K}_{2} \mathrm{O}$ e $\mathrm{MgO}$ dessas rochas, para a sua alta razão $\mathrm{K}_{2} \mathrm{O} / \mathrm{TiO}_{2}$, $\mathrm{P}_{2} \mathrm{O}_{5} / \mathrm{TiO}_{2}$ e $\mathrm{K}_{2} \mathrm{O} / \mathrm{Nb}$, além de assinalar que essa ocorrência pertence a uma suíte potássica a ultrapotássica.

Gomes et al. (1989) forneceram informaçōes sobre o enxame de diques da área de Sapucai. $\mathrm{O}$ estudo envolveu pesquisa detalhada do ponto de vista petrográfico, além de ter possibilitado a reunião de grande acervo de dados geoquímicos, que foram modelados em diferentes diagramas de variação e acompanhados de cálculos de balança de massa. Segundo esses autores, as associações litológicas presentes nos diques, onde se distinguem 
diversos tipos de basaltos alcalinos (ri$\cos$ e pobres em elementos incompativeis) ou mesmo fonolitos, exibindo grau variável de evolução, não se acham relacionadas entre si por simples processos de cristalizaçåo fracionada. Assim, é possivel que os diversos magmas alcalinos representados na área possam ter tido uma evolução a baixa pressão a partir de uma fonte mantélica submetida a grau diferente de fusão.

Comin-Chiaramonti et al. (1990) realizaram estudos petrográficos e químicos (minerais e rochas) para as diversas litologias do maciço alcalino de Acahay, e promoveram exaustiva discussão sobre a sua gênese e evolução. Para esses autores, os dados químicos e petrográficos testemunham que o maciço é constituído em sua maior parte por duas suites (extrusiva e intrusiva), com as rochas, em função da sua afinidade, incluídas em três grupos distintos: a) traquibasaltos-traquiandesitos-traquitos, b) gabros alcalinos-sienogabros-sienodioritos-sienitos e c) gabros essexitos-essexitos. Além disso, assinalaram que o comportamento dos elementos maiores e traços para esses grupos parece indicativo de uma gênese comum tendo como magma parental os gabros alcalinos. Esse magma é interpretado como sendo o produto de grau diferente de fusão $(4-7 \%)$ de um manto granatifero, submetido a processos de cristalização fracionada que levaram à formação dos termos mais evoluídos.

Velázquez et al. (1990) fizeram uma primeira avaliação sobre as características geoquímicas de alguns corpos alcalinos potássicos aflorando na área do rift Assunção-Sapucai, oferecendo informações sobre as razões $\mathrm{La} / \mathrm{Nd}$, $\mathrm{La} / \mathrm{Y}, \mathrm{La} / \mathrm{Nb}$ e $\mathrm{Rb} / \mathrm{Sr}$ dessas rochas, que serviram de subsídio para a definição da sua área fonte.

Em termos gerais, as tendências geoquímicas observadas para o magma- tismo potássico revelam valores de $\mathrm{Mg}$ e conteúdos de $\mathrm{Cr}$ e $\mathrm{Ni}$ relativamente baixos. Por outro lado, a notável dispersão registrada para as razões $\mathrm{La} / \mathrm{Nd}$, $\mathrm{La} / \mathrm{Y}, \mathrm{Zr} / \mathrm{Nb}$ e $\mathrm{Rb} / \mathrm{Sr}$ parece indicar uma origem ligada a fontes heterogêneas e/ou grau de fusão diferente para um manto com fases hidratadas no resíduo. Em geral, essas características geoquimicas guardam similaridades com as exibidas pelas rochas vulcânicas potássicas da Província Romana (CominChiaramonti et al., 1991a).

Dados radiométricos e isotópicos (razão inicial ${ }^{87} \mathrm{Sr} /{ }^{86} \mathrm{Sr}$ ) constantes dos trabalhos de Velázquez et al. (1990, 1992) são indicativos de que essa atividade alcalina potássica teve lugar principalmente entre 130 e $120 \mathrm{Ma}$; estes valores são consistentes com as informações obtidas por meio de análises paleomagnéticas (130 Ma; $\mathrm{cf}$. Ernesto et al., 1990). Por outro lado, a razão inicial apresenta pequena dispersão, agrupando-se entre 0,70685 e 0,70792 , à exceção dos plugs fonolíticos de Cerro Gimenez e Cerro Medina, de natureza sódica, que mostram valores bem mais baixos, respectivamente, 0,70247 e 0,70324 .

\section{Província Misiones}

$\mathrm{Na}$ regiāo sudoeste do país, junto ao Departamento de Misiones, nas proximidades das localidades de Estancia Guavira-y, Estancia Ramirez e Cerro Caá Jhovy, encontram-se pequenos plugs e dique de rochas alcalinas associados discordantemente a arenitos triássicos da Formação Misiones (Fig. 1F). Os plugs apresentam diâmetro de 0,3 a $0,8 \mathrm{~km}^{2}$ e altura média não superior a $50 \mathrm{~m}$; por sua vez, o dique possui largura aproximada de $10 \mathrm{~m}$ e orientação para NW.

Os dados disponíveis são ainda insuficientes para se estabelecer o regime tectônico desse magmatismo, porém, as evidências de campo parecem 
indicar que esses corpos se acham condicionados a lineamentos regionais de direção NW, avaliados por DeGraff \& Orué (1984) como resultado de fraturamento crustal, admitindo-se um deslocamento de $2000 \mathrm{~m}$ em relação ao embasamento situado a NE da estrutura.

As rochas que ocorrem nas localidades Estancia Guavira-y e Estancia Ramirez foram classificadas como nefelinitos. A textura é tipicamente porfirítica, com clinopiroxênios e olivina como feno e microfenocristais. A matriz hipocristalina é constituída de vidro vulcânico, clinopiroxênios, olivina, opacos e feldspatóides. À diferença das outras ocorrências, em Cerro Caá Jhovy, afloram fonolitos peralcalinos, dominantemente porfiriticos, com feldspato alcalino como fenocristais e grãos isolados de opacos como microfenocristais, imersos em matriz consistindo em micrólitos de clinopiroxênio e feldspato alcalino (Comin-Chiaramonti et al, 1992b).

Evidências geoquímicas para elementos maiores e traços indicam diferenças marcantes entre os nefelinitos de San Juan Bautista e aqueles aflorando na área de Assunção, assim como dos traquitos de Cerro Caá Jhovy em relação às rochas congêneres da Provincia Central (Comin-Chiaramonti et al., 1992b).

Pouco se sabe sobre a idade desses corpos, com a única datação disponivel (112 $\pm 6 \mathrm{Ma}$, J.M. DeGraff, dados inéditos) dizendo respeito aos fonolitos de Cerro Caá Jhovy. Mais recentemente, Comin-Chiaramonti et al. (1992b), utilizando a equação de $\mathrm{Rb} / \mathrm{Sr}$, calcularam novos valores de idade convencional para essas rochas, 145,7 e 91,3 $\mathrm{Ma}$, estes, apesar da limitação dos dados, mostrando boa correspondência com o magmatismo alcalino mesozóico das porções central e nordeste do Paraguai Oriental.

\section{Província Assunção}

A maioria dos afloramentos localiza-se nas circunvizinhanças da cidade de Assunção (Fig.1D). A denominação de Província Assunção para essas ocorrências é devida a Bitschene et al. (1985). No total, ela reúne 11 corpos principais, na forma de plugs, necks, lavas e diques, entre os quais se destacam os de Cerros Ñemby e Tacumbú, presentemente trabalhados como pedreira. Tectonicamente, acham-se associados ao rift de Assunção, concentrando-se na sua porção ocidental. A ocorrência dessas rochas na região marca uma importante atividade tectono-magmática durante o Cenozóico. Coube a Milch (1905), a primeira resenha sobre esse magmatismo, trazendo informações sobre a sua distribuição geográfica, além de uma sucinta caracterização petrográfica. Segundo esse autor, a manifestação corresponde a uma associação de rochas ultramáficas do tipo limburgito.

Trabalhos posteriores demonstraram que essas rochas pertencem a uma suíte reunindo dominantemente nefelinitos e ankaratritos em proporção menor, com tendência marcadamente sódica, e contendo nódulos mantélicos. Em geral, os nefelinitos são rochas escuras de granulação fina e levemente porfiriticas, portadoras de fenocristais de olivina, com dimensões aproximadas de $2 \mathrm{~mm}$, e, subordinadamente, de clinopiroxênios (Stormer et al., 1975; Bitschene, 1987; Comin-Chiaramonti et al., 1991c). Ao microscópio, os piroxênios são fortemente zonados, além de exibirem coroa de reação. Os fenocristais de olivina são xenomórficos, sem zoneamento, e com evidências de deformação autoclástica. A matriz é afanítica, consistindo predominantemente em clinopiroxênios, olivina, opacos e nefelina; ocasionalmente, aparecem micrólitos de plagioclásio e vidro intersticial. Micronódulos e presumíveis xenocristais $(0,2$ 
até $2 \mathrm{~mm}$ ) são relativamente comuns (Stormer et al., 1975; Bitschene \& Báez Presser, 1989).

Os nódulos mantélicos presentes nos nefelinitos possuem composição variável de lherzolito a dunito. Mineralogicamente, acham-se constituídos por olivina e piroxênios (orto e clino), tendo espinélio como principal acessório. A textura é dominantemente xenomórfica granular, onde a olivina mostra extinção ondulante e deformação lamelar, enquanto os piroxênios são xenomórficos, com abundantes lamelas de exsolução. O espinélio é intersticial e de ocorrência irregular (Comin-Chiaramonti et al., 1986; De Vito, 1987; Demarchi et al., 1989).

Essas ocorrências, como evidenciado na literatura, foram objeto de diversos trabalhos geoquímicos. Stormer et al. (1975), com base no estudo do quimismo dos minerais, concluíram que as condições de equilibrio paragenético foram atingidas a uma temperatura de $1100^{\circ} \mathrm{C}$ e profundidade de aproximadamente $45 \mathrm{~km}$. Bitschene (1987) e Bitschene \& Báez Presser (1989) sugeriram que essas lavas alcalinas teriam se derivado a partir de magma primitivo gerado no manto superior, como indicado pela concentração de $\mathrm{Cr}, \mathrm{Ni}, \mathrm{Mg}$ e razão $\mathrm{Zr} / \mathrm{Nb}$. Comin-Chiaramonti et al. (1991c), com base em dados isotópicos e geoquímicos, propuseram para a gênese dos nefelinitos uma derivação a partir de uma fonte de granada peridotito, posteriormente enriquecida em elementos incompatíveis por processos metasomáticos. Concordantemente com a hipótese do metassomatismo, têm-se as conclusões de Demarchi et al. (1989) sugerindo que esses processos acham-se relacionados petrogeneticamente a uma atividade enérgica de fluidos ricos em $\mathrm{H}_{2} \mathrm{O}+\mathrm{CO}_{2}$, causada por uma perturbação do gradiente geotérmico responsável pelo vulcanismo toleítico da Bacia do Paraná.
Estudos radiométricos dos nefelinitos foram feitos por diversos autores. Comte \& Hasui (1971), empregando $\mathrm{K} / \mathrm{Ar}$ em rocha total, determinaram uma idade de $46 \pm 7 \mathrm{Ma}$ para o nefelinito de Cerro Tacumbú. Recorrendo à mesma metodologia, Stormer et al. (1975) obtiveram uma idade de $36 \pm 11$ Ma para o basanito da localidade de Cerrito Cantera. Contudo, os dados mais completos são os fornecidos por Bitschene (1987) e por Comin-Chiaramonti et al. (1991c), que indicam um intervalo de idade compreendido entre 61-37 Ma para os nefelinitos da Província Assunção, o que permite situá-la no Terciário.

\section{CONSIDERAÇÕES FINAIS}

A síntese apresentada sobre o magmatismo alcalino do Paraguai permite verificar que as numerosas ocorrências, aqui agrupadas em seis províncias, estão ligadas a distintos processos genéticos e evolutivos, atuando num período de tempo consideravelmente prolongado. Além disso, cabe assinalar a estreita relação entre a tectônica regional e a atividade magmática. Nesse sentido, a influência do arcabouço estrutural da Bacia do Paraná parece ter exercido papel preponderante.

Embora a avaliação dos dados geocronológicos, petrográficos e geoquímicos em algumas ocorrências ainda demande reservas, as distintas províncias mostram diferenças significativas quanto à composição e época de colocação na crosta continental. Assim, a Província Alto Paraguai congrega rochas sieníticas de natureza fortemente insaturada a saturada e afinidade sódica, que se formaram principalmente no Permo-Triássico. Já os poucos dados disponiveis para a Provincia Rio Apa sugerem uma associação alcalina carbonatítica, representada por diques de idade Juro-Cretáceo (145-150 Ma, V.F. Velázquez, dados inéditos). A Provín- 
cia Amambay corresponde a uma atividade de associação claramente alcalina carbonatítica, tendo os complexos anelares dos Cerros Chiriguelo e Sarambí como principais representantes. Os dados geocronológicos existentes para essa provincia indicam que a atividade alcalina se deu no período Juro-Cretáceo. Por outro lado, a Província Central representa um magmatismo de afinidade dominantemente potássica, envolvendo rochas do tipo gabros essexitos (basaltos alcalinos), essexitos (tefritos), sienitos (traquitos) e seus diferenciados, que se manifestou fundamentalmente no Cretáceo. A colocação dos corpos nefeliníticos da Província Assunção, ocorrido no Terciário, assinala importante atividade ígnea, reunindo rochas de afinidade ultrabásica alcalina portadoras de nódulos mantélicos. Esse magmatismo, além de fornecer amplo panorama sobre o comportamento geotermo-tectônico, oferece também valiosas informações a respeito do equilibrio termodinâmico do manto sublitosférico. Referente à Província Misiones, que inclui rochas vulcânicas do tipo nefelinítico e fonolítico, pouco ainda se sabe, com as poucas informações existentes indicando tratar-se de um magmatismo diferente daquele das Províncias Assunção e Central.

Ainda que no Paraguai sejam pou$\cos$ os trabalhos que enfatizam a distribuição geográfica do magmatismo e a sua relação com os elementos tectôni$\cos$, os dados disponíveis sugerem basicamente três tipos principais de associação: a) margem cratônica ou área tectonicamente estável, caso das Províncias Alto Paraguai e Rio Apa; b) zonas de arcos estruturais ou intercessão de alinhamentos tectônicos, como exemplificado pela Província Amambay e c) rift continental, caso das Províncias Central, Assunção e Misiones.

Finalmente, pode-se acrescentar que os dados geocronológicos permitem reconhecer com muita clareza que as manifestações alcalinas sofreram fases de descontinuidade e, adicionalmente, constatar a existência de épocas com maior pulso magmático em cada periodo. Por outro lado, as idades sugerem também que as atividades igneas tiveram início ao norte, no período PermoTriássico, espalhando-se posteriormente pelas regiões nordeste, central e sul do pais, no Cretáceo e Terciário.

\section{AGRADECIMENTOS}

Estes são devidos à FAPESP (Proc. 90/3692-7) e ao MURST 40\%, Itália, pelo apoio financeiro.

\section{REFERÊNCIAS BIBLIOGRÁFICAS}

ALMEIDA, F.F.M. (1971) Condicionamento tectônico do magmatismo alcalino mesozóico do Sul do Brasil e do Paraguai Oriental. Anais da Academia Brasileira de Ciências, v.43, n.3-4, p.835-836.

ALMEIDA, F.F.M. (1983) Relações tectônicas das rochas mesozóicas da região meridional da Plataforma Sul-Americana. Revista Brasileira de Geociências, v.13, n.3, p.139258.

AMARAL, G. (1984) Províncias Tapajós e Rio Branco; In: ALMEIDA, F.F.M.; HASUI, Y. (eds.) O PréCambriano do Brasil. Editora Edgard Blücher, Ltda., São Paulo, p.735.

AMARAL, G.; BUSHEE, J.; CORDANI, U.G.; KAWASHITA, K.; REYNOLDS, J.H. (1967) Potassium-argon ages of alkaline rocks from Southern Brazil. Geochimica et Cosmochimica Acta, v.31, p.117142.

BITSCHENE, P.R. (1987) Mesozoicher und kanosozoicher magmatimus in Ost-Paraguay: arbeinteznur Geologie und Petrolo- 
gie zweier Alkaliprovinzen. Heidelberg, 317p. (Tese de Doutorado), Universidade de Heidelberg.

BITSCHENE, P.R.; BÁEZ PRESSER, J. (1989) The Asunción Alkaline Province (Eastern Paraguay): geologic setting and petrogenetic aspects. Zentralblatt für Geologie und Paläontologie. Teil $\mathrm{I}, \mathrm{v} .5 / 6$, p.959-971.

BITSCHENE, P.R.; LIPPOLT, H.J. (1984) Geologie der Cordillera der Ybytyruzú in Ost-Paraguay: ein Mesozoicher alkali-intrusiv-komplex am westrand der Parana-beckens. Lateinamerica - Kolloquium Marbug, Tag., Heft., v.9, p.33-34.

BITSCHENE, P.R.; LIPPOLT, H.J.; ARETZ, J. (1985) Tertiarer vulcanismus in Ost-Paraguay (AsunciónProvinz) und rifting prozesse am westrand der Sudamerika-nischen platform. Fortschritte der Mineralogie, v.63, n.1, p.26.

BITSCHENE, P.R.; LIPPOLT, H.J.; EMMERMANN, R. (1986) Jungmesozoicher $\mathrm{K}$-betonter magmatismus in Ost-Paraguay (Guairá-Paraguari Provinz) und rifting-prozesse innerhalb der Sudamericka-platform. Fortschritte der Mineralogie, v.64, n.1, p.19.

CENSI, P.; COMIN-CHIARAMONTI, P.; DE MIN, A.; GOMES, C.B.; ORUÉ, D.; PETRINI, R.; PICCIRILLO, E.M.; VELAZQUEZ, V.F. (1991) "Plugs" fonolíticos no Gráben Assunção-Sapucai, Paraguai CentroOriental. In: CONGRESSO BRASILEIRO DE GEOQUÍMICA, 3./ CONGRESSO DE GEOQUIMICA PLOP, 1., São Paulo, 1991. Resumos, São Paulo, SBGq/Sociedade Geológica de Portugal/IG-USP, v.1, p.127-129.

CENSI, P.; COMIN-CHIARAMONTI, P.; DE MARCHI, G.; ORUÉ, D. (1989) Geochemistry and C-O isotopes of the Chiriguelo carbonatite
(Northeastern Paraguay). Journal of South American Earth Sciences, v. 2, n.3, p. 295-303.

COMIN-CHIARAMONTI, P.; DEMARCHI, D.; GIRARDI, V.A.V.; PRINCIVALLE, F; SINIGOI, S. (1986) Evidence of mantle metasomatism and heterogeneity from peridotite inclusions of northeastern Brazil and Paraguay. Earth Planetary Science Letters, v.77, n.2, p.203-217.

COMIN-CHIARAMONTI, P.; GOMES, C.B.; PICCIRILLO, E.M.; BELLIENI, G.; CASTILLO, A.M.C.; DEMARCHI, G.; GALLO, P.; VELÁZQUEZ, J.C. (1990) Petrologia do maciço alcalino de Acahay, Paraguai Oriental. Revista Brasileira de Geociências, v.20, p.133152.

COMIN-CHIARAMONTI, P.; CAPALDI, G.; CENSI, P.; CUNDARI, A.; DE MIN, A.; GOMES, C.B.; ORUÉ, D.; PETRINI, R.; PICCIRILLO, E.M.; VELÁZQUEZ, V.F. (1991a) Geoquímica dos complexos alcalinos potássicos do Paraguai Centro-Oriental. In: CONGRESSO BRASILEIRO DE GEOQUÍMICA, 3./CONGRESSO DE GEOQUIMICA PLOP, 1., São Paulo, 1991. Resumos, São Paulo, SBGq/Sociedade Geológica de Portugal, IG-USP, v.1, p.100-108.

COMIN-CHIARAMONTI, P.; CAPALDI, G.; CENSI, P.; CUNDARI, A.; DE MIN, A.; GOMES, C.B.; ORUÉ, D.; PETRINI, R.; PICCIRILLO, E.M.; VELÁZQUEZ, V.F. (1991b) Geochemistry of mesozoic $\mathrm{K}$-alkaline complexes from centraleastern Paraguay. Plinius, v.6, p.149-153.

COMIN-CHIARAMONTI, P.; CIVETTA, L.; PETRINI, R.; PICCIRILLO, E.M.; BELLIENI, G.; CENSI, P.; BITSCHENE, P.R.; DEMARCHI, G.; DE MIN, A.; GOMES, 
C.B.; CASTILLO, A.M.C.; VELÁZQUEZ, J.C. (1991c) Tertiary nephelinitic magmatism in Eastern Paraguay: petrology, Sr-Nd isotopes and genetic relationships with associated spinel-peridotite xenoliths. European Journal of Mineralogy, v. 3 , n. 3 , p. $507-525$.

COMIN-CHIARAMONTI, P; CUNDARI, A.; CENSI, P.; GOMES, C.B.; PICCIRILLO, E.M.; BELLIENI, G.; DE MIN, A.; ORUÉ, D.; VELÁZQUEZ, V.F. (1991d) Mesozoic dyke swarm in the Sapucai-Graben (Central-eastern Paraguay). In: INTERNATIONAL SYMPOSIUM ON MAFIC DYKES, São Paulo, 1991. Extended Abstracts, São Paulo, SBGq, p.125-132.

COMIN-CHIARAMONTI, P; CUNDARI, A.; GOMES, C.B.; PICCIRILLO, E.M.; CENSI, P.; DE MIN, A.; BELLIENI, G.; VELÁZQUEZ, V.F.; ORUE, D. (1992a) Potassic dyke swarm in the SapucaiGraben eastern Paraguay: petrographical, mineralogical and geochemical outlines. Lithos, v.28, n.34, p.283-301.

COMIN-CHIARAMONTI, P.; GOMES, C.B.; PETRINI, R.; DE MIN, A.; VELÁZQUEZ, V.F.; ORUÉ, D. (1992b) A new area of alkaline rocks in Eastern Paraguay. Revista Brasileira de Geociências, v.22, n.4, p.500-506.

COMTE, D.; HASUI, Y. (1971) Geocronology of eastern Paraguay by potassium-argon method. Revista Brasileira de Geociências, v.9, p. 59-88.

DE MIN, A. (1988) Studio petrologico e geochimico della atività filoniana alcalina di Sapucai (Paraguay). Trieste, 210p. (Tese - Láurea), Universidade de Trieste.

DE VITO, P. (1987) Studio petrologico di xenoliti peridotici del Paraguay: implicazioni relative a meta- somatismo di mantelo. Trieste, 210p. (Tese - Láurea), Universidade de Trieste.

DEGRAFF, J.M. (1985) Late mesozoic crustal extension and rifting on the western edge of the Paraná $\mathrm{Ba}$ sin, Paraguay. Abstracts of the Geological Society of America, v. 17, p. 560 .

DEGRAFF, J.M; ORUÉ, D. (1984) Proyeto tectónico del Paraguay Suroriental: informe de progreso al termino del trabajo de campo. Asunción, MDN-DIM 12p. (Relatório Interno).

DEMARCHI, G.; COMIN-CHIARAMONTI, P.; DE VITO, P.; SINIGOI, S.; CASTILLO, A.M.C. (1989) Lherzolite-dunite xenoliths from eastern Paraguay: petrological constraints to mantle metasomatism. In: PICCIRILLO, E.M.; MELFI, A.J. (eds.) The Mesozoic flood vulcanism from the Paraná Basin: petrogenetic and geophysical aspects. São Paulo, LAG, p.207-227.

DERBY, O.A.A. (1896) Notas sobre a geologia e paleontologia de Mato Grosso. Archivo do Museu Nacional, v.9, p.59-88.

EBY, G.N.; MARIANO, A.N. (1986) Geology and geocronology of carbonatites of the Paraná Basin, BrazilParaguay. In: CARBONATITES SYMPOSIUM, Ottawa, 13p.

EBY, G.N.; MARIANO, A.N. (1992) Geology and geochronology of carbonatites and associated alkaline rocks peripheral to the Paraná Basin, Brazil-Paraguay. Journal of South American Earth Sciences, v.6, n.3, p. 207-216.

ECKEL, E.B. (1959) Geology and mineral resources of Paraguay: a reconnaissance. U.S. Geological Survey, Professional Paper, v.34, p.1-110.

ERNESTO, M.; RODAS, C.S.R; COMIN-CHIARAMONTI, P.; GOMES, 
C.B.; PICCIRILO, E.M.; BELLIENI, G.; CASTILLO, A.M.C.; VELÁZQUEZ, J.C.; CUNDARI, A. (1991) Paleomagnetismo de los diques asociados al complejo alcalino de Sapucai, Paraguay Oriental. ler. Coloquio de Rocas Magmaticas de Paraguay, San Lorenzo, Paraguay. Revista Geologica. Asociación de Geólogos del Paraguay. v.1, p.125-128.

EVANS, J.W. (1894) The geology of Mato Grosso. Quartely Journal of the Geological Society of London, v.50, p.85-104.

GALLO, P. (1988) Studio petrografico del massiccio alcalino di Acahay (Paraguay Oriental), Palermo, 188p. (Tese - Láurea), Universidade de Palermo.

GOMES, C.B.; COMIN-CHIARAMONTI, P.; DE MIN, A.; MELFI, A.J.; BELLIENI, G.; ERNESTO, M.; CASTILLO, A.M.C.; VELÁZQUEZ, V.F. (1989) Atividade filoniana associada ao complexo alcalino de Sapucai, Paraguai Oriental. Geochimica Brasiliensis, v.3, n.2, p.93-114.

GOMES, C.B.; COMIN-CHIARAMONTI, P.; DE MIN, A.; ROTOLO, S.G.; VELAZZUUEZ, V.F. (1993) A Provincia Alcalina do Alto Paraguai (Mato Grosso do Sul e Paraguai): características geoquímicas. In: CONGRESSO BRASILEIRO GEOQUÍMICA, 4., Brasilia, 1993, Resumos Expandidos, Brasilia, SBGq, p.55-58.

GOMES, C.B.; COMIN-CHIARAMONTI, P.; VELÁZQUEZ, V.F.; ORUÉ, D. (1996) Alkaline magmatism in Eastern Paraguay: a review. In: COMIN-CHIARAMONTI, P.; GOMES, C.B. (eds.), Alkaline magmatism in Central Eastern Paraguay. Relationships with coeval magmatism in Brazil. São Paulo, EDUSP/FAPESP, p.31-56.

GUIMARÃES, D. (1958) Rochas al- calinas da região Fecho dos Morros no Sul do Mato Grosso e República do Paraguai. Estudos petrográficos dos sienitos da região do Fecho dos Morros. Anais da Academia Brasileira de Ciências, v.30, p.171174.

HALES, F.W. (1980) An interpretation of the data from the airborne magnetic surveys in northern areas of eastern Paraguay. Asunción, DRMMOPC/T.A.C. 119p. (Relatório Interno).

HUTCHISON, D.S. (1979) Geology of the Apa High. Asunción, DRMMOPC/T.A.C. 24p. (Relatório Interno).

HUTCHISON, D.S. (1980) Reconnaissance exploration in the Apa High. Asunción, DRM-MOPC/ T.A.C. 13p. (Relatório Interno).

LIVIERES, R.A. (1987) Der karbonatite-komplex von Chiriguelo Nordost-Paraguay. Clausthal, 191p. (Tese - Doutorado), Universidade de Clausthal.

LIVIERES, R.A.; QUADE, H. (1987) Distribución regional y asentamiento tectónico de los complejos alcalinos del Paraguay. Zentralblatt für Geologie und Paläontologie. Teil I, v. $7 / 8$, p.791-805.

MARIANO, A.N. (1978) Report on alkaline rocks. Exploration in southern Paraguay and supplement an exploration in the area of Pedro Juan Caballero. Asunción, DRMMOPC/T.A.C. 134p. (Relatório Interno).

MILCH, L. (1905) Über die chemische zusammensetzung eines limburgites, eines phonolithischen gesteines und einiger sandsteine aus Paraguay. Tschermak's Mineralogische und Petrographische Mitteilungem, v. 24, p.213-226.

MORAES, L.J. (1958) Rochas alcalinas da região Fecho dos Morros, no Sul de Mato Grosso e República do Pa- 
raguay. Distribuição geográfica das montanhas sieníticas do Fecho dos Morros. Anais da Academia Brasileira de Ciências, v. 10, p.1-27.

PALMIERI, J.H. (1973) El complejo alcalino potásico de Sapucai (Paraguay Oriental), Salamanca, 298p. (Tese - Doutorado), Universidade de Salamanca.

PALMIERI, J.H.; ARRIBAS, A. (1975) El complejo alcalino potásico de Sapucai (Paraguay Oriental). In: CONGRESO IBERO-AMERICANO DE GEOLOGIA ECONOMICA, Buenos Aires, 1975, Anais. Buenos Aires, Argentina, La Geologia en Desarrollo de los Pueblos, v.2, p.257-300.

PROJETO BODOQUENA (1979) Geologia das regiões centro e oeste do Mato Grosso do Sul. Rio de Janeiro, MME, 111p. (Série Geológica, Seção Geologia Básica, v.3).

PROJETO PAR 83/005-PNYD-MDN (1986) Mapa geológico del Paraguay: texto explicativo. Asunción, $270 \mathrm{p}$.

PROJETO RADAMBRASIL (1982) Folha SF-21 Campo Grande: geologia, geomorfologia, pedologia, vegetação e uso da terra. Rio de Janeiro, MME. 416p. (Levantamento de Recursos Naturais, 28).

PUTZER, H. (1962) Die geologie von Paraguay. Beitraege zur Regionaler Geologie der Erde, v.2, p.182.

PUTZER, H.; VAN DEN BOOM, G. (1962) Über einige volkommen von alkaligesteinen in Paraguay. Geologische Jarbuch, v.79, p.423-444.

STORMER, J.C.; GOMES, C.B.; TORQUATO, J.R.F. (1975) Spinel lherzolite nodules in basanites lavas from Asunción, Paraguay. Revista Brasileira de Geociências, v.5, p.176-185.

THOMAS \& ASSOCIATES (1976) Preliminary Erts interpretation southeastern Paraguay. Asunción, DRMMOPC/T.A.C., 20p. (Relatório In terno).

ULBRICH, H.H.G.J.; GOMES, C.B. (1981) Alkaline rocks from continental Brazil. Earth Science Reviews, v.17, n.1-2, p.135-154.

VELÁZQUEZ, V.F. (1992) Província Alcalina Central, Paraguai centrooriental: aspectos tectônicos, petrográficos e geocronológicos. São Paulo, 119p. (Dissertação - Mestrado) - Instituto de Geociências, Universidade de São Paulo.

VELÁZQUEZ, V.F. (1996) Província Alcalina Alto Paraguai: características petrográficas, geoquímicas e geocronológicas. São Paulo, 101p. (Tese - Doutorado) - Instituto de Geociências, Universidade de São Paulo.

VELÁZQUEZ, V.F.; DE MIN, A.; COMIN-CHIARAMONTI, P; GOMES, C.B.; PICCIRILLO, E.M.; VELÁZQUEZ, J.C. (1990) Vulcanismo mesozóico no Paraguai centro-oriental (Área Ypacarai-Sapucai). In: COLÓQUIO DE ROCAS MAGMÁTICAS DEL PARAGUAY. Asunción, 1990, Resumo. Paraguay, Universidade Nacional, Faculdad Ciências Exactas.

VELÁZQUEZ, V.F.; GOMES, C.B.; CAPALDI, G.; COMIN-CHIARAMONTI, P.; ERNESTO, M.; KAWASHITA, K.; PETRINI, R.; PICCIRILLO, E.M. (1992) Magmatismo alcalino mesozóico na porção centro-oriental do Paraguai: aspectos geocronológicos. Geochimica Brasiliensis, v.6, p.23-35.

VELÁZQUEZ, V.F.; GOMES, C.B.; COMIN-CHIARAMONTI, P.; TASSINARI, C.C.G.; TEIXEIRA, W. (1993) Geocronologia da Província Alcalina do Alto Paraguai (Área Puerto Guaraní-Porto Murtinho): considerações preliminares. CONGRESSO BRASILEIRO DE GEOQUíMICA, 4., Brasilia, 1993, Resumos Expandidos, Brasília, SBGq., 
p. 245 .

VELÁZQUEZ, V.F.; KAWASHITA, K.; GOMES, C.B.; COMIN-CHIARAMONTI, P. (1991) Província Alcalina Central, Paraguai: dados geocronológicos preliminares. $\mathbf{R e}-$ vista de Geologia, v.1, p.117.

WILLOUGHBY, N.O. (1979) The geology and economic potencial of the Centurion High (North-eastern Paraguay). Asunción, DRM-MOPC/ T.A.C., 20p. (Relatório Interno).

V.L.Velázquez - Instituto de Geociências, Universidade de São Paulo, Caixa Postal 11.348, CEP 05422-970, São Paulo, SP, Brasil. 